\title{
The Influence of Atmospheric Blocking on the Rossby Wave Propagation in Southern Hemisphere Winter Flows
}

\author{
Ernani de Lima NASCIMENTO and Tércio AMBRIZZI \\ Department of Atmospheric Sciences, Institute of Astronomy, Geophysics and Atmospheric Sciences, \\ University of São Paulo, Brazil
}

(Manuscript received 6 December 2000, in revised form 28 August 2001)

\begin{abstract}
The influence of blocking systems on the propagation of planetary Rossby waves is investigated over the South Pacific. Two episodes of blocked flow observed during the winter of 1995 in the Southern Hemisphere were selected for this purpose. Rossby wave activity is analyzed with the aid of a barotropic model linearized around zonally and meridionally varying basic states obtained from the National Centers for Environmental Prediction Center (NCEP)/National Center for Atmospheric Research (NCAR) Reanalysis Project data. Basic state flows corresponding to the blocking events, and to the seven-day period immediately prior to (after) their onset (decay) were used. The forcing, represented by an anomalous divergence pattern, is placed in two different regions-tropics and subtropics. Numerical results are discussed based on the linear theory for Rossby wave propagation. Fields of stationary wavenumber $\left(K_{S}\right)$ for barotropic Rossby waves are computed for the basic state flows. Wave activity fluxes are calculated for the perturbation fields.

The spatial distribution of $K_{S}$ showed the jet streams as potentially efficient waveguides, as indicated by the agreement between the position of the jet stream axes and the relative maxima of $K_{S}$. A tendency for increasing values of $K_{S}$ in the high latitudes (south of $65^{\circ} \mathrm{S}$ ) was obtained along the poleward flank of the longitudinal zone where the blocking systems were positioned. This suggests a possible enhancement on Rossby wave activity along sub-polar regions during these blocking events. In contrast, for the periods preceding and subsequent to the blocking systems, values of $K_{S}$ at high latitudes did not show a tendency to increase, characterizing a normal situation in which local maximum values of $K_{S}$ are confined to the mid- and subtropical latitudes. The numerical results suggest that the planetary Rossby wave propagation can be influenced by this alteration in the latitudinal distribution of higher values of $K_{S}$ during the life cycle of the blocking systems. A transition, from subtropical to sub-polar, of the main sector of wave propagation was obtained between the pre-blocking and blocking situations, and with the subtropical Rossby wave activity regaining importance after the decay of the blocking events.

Moreover, for situations preceding the blocking systems, a region of maximum values on wave activity flux was obtained on the longitudinal zone where the blocking patterns would develop subsequently, indicating a possible participation of stationary Rossby wave propagation on the onset of the blocking episodes.
\end{abstract}

\section{Introduction}

Blocking patterns are frequently responsible for seasonal anomalies of meteorological pa-

Corresponding author and Current affiliation: Ernani L. Nascimento, The University of Oklahoma, School of Meteorology, Sarkeys Energy Center, Room 1310, Norman, OK 73019-0470, USA.

E-mail: nascimento@ou.edu

(C) 2002, Meteorological Society of Japan rameters, such as temperature and precipitation, over wide-ranging areas and lasting from a few days to several weeks. Our knowledge about the influence of these systems on the atmospheric flow has evolved considerably since the early investigations by Daniel F. Rex (e.g., Rex 1950). Nevertheless, the difficulty in predicting the onset of blocking in an operational setting reveals the need for improving not only 
our understanding about the mechanisms that influence their life cycle (Tibaldi et al. 1994, 1995; Colucci and Baumhefner, 1998), but also about how the presence of such systems affect the atmospheric flow in different scales of motion.

The large number of investigations focusing on the influence of high-frequency mechanisms on the formation, maintenance and decay of blocking systems confirm the relevance and complexity of the subject. Several numerical and observational studies, such as Hansen and Chen (1982), Illari and Marshall (1983), Shutts (1983, 1986), Egger and Müller (1986), Metz (1986), Mullen (1987) and Holopainen and Fortelius (1987) showed the importance of the role played by the eddy fluxes on the formation and maintenance of blocking. Tsou and Smith (1990) discussed the interaction between amplifying blocking ridges, and the migratory transient perturbations. They concluded that the transients exert a positive feedback that acts to reinforce the blocking ridge. Similarly, Nakamura and Wallace (1993) showed that the amplification of some blocking anticyclones follows an abnormally high activity of migratory perturbations associated with explosive cyclogenesis (Colucci and Alberta 1996).

Many studies also present evidence that low frequency dynamics in the atmosphere are relevant to blocking development (Austin 1980; Karoly 1983b; Lindzen 1986; Lejenäs and Madden 1992; Naoe et al. 1997). Nakamura (1994) indicated that the amplification of intense blocking episodes over Europe is related to the propagation of quasi-stationary Rossby waves across the North Atlantic Ocean. He showed that a wavetrain emanating downstream from the blocked longitude appears as the blocking ridge weakens, and hypothesized that the absorption of wave activity and its re-emission could lead, respectively, to the formation and decay of the intense blocking anticyclones over Europe. His results suggest that the low frequency dynamics of the atmosphere respond to different stages of the life cycle of blocking systems over the North Atlantic. Employing a barotropic model, Naoe et al. (1997) studied the Rossby wave propagation in a winter blocked flow, and obtained results that agree with the ones obtained by Nakamura (1994).

Buizza and Molteni (1996) examined the importance of barotropic instability for the evo- lution of blocking patterns during the winter 1990/91 using the singular vector approach applied to a barotropic model. They reproduced dipole structures (resembling the observed blocking patterns) that gained kinetic energy from the planetary scale flow through barotropic conversion when the magnitude of the longitudinal gradient of the basic state wind speed on the jet exit was comparable to its latitudinal gradient in the jet core. They indicated that this was possible in the presence of an anomaly amplifying the ridge on the eastern side of the Atlantic and Pacific oceans (i.e., downwind of the jet streams).

More recently, studies employing distinct approaches provided additional evidence that baroclinic and barotropic processes in the atmosphere interact with blocking systems (Nakamura et al. 1997; Pondeca et al. 1998; Li et al. 1999). In particular, Nakamura et al. (1997) analyzed a composite time evolution of thirty strong blocking episodes observed over Europe, and the North Pacific. They showed that eddy fluxes associated with the migratory perturbations are not the major mechanism for the amplification of blocking ridges over Europe, accounting for less than $50 \%$ of the process. For this region most of the blocking amplification was attributed to interactions with quasistationary barotropic Rossby waves (Nakamura 1994). On the North Pacific, however, their results indicated that low frequency dynamics played a secondary role on the process of blocking formation and maintenance. For this sector, synoptic perturbations evolving along the storm tracks impose a significant positive feedback for the intensification of blocking, accounting for more than $75 \%$ of the process.

Some recent studies explored blocked flows also in the South Pacific zone (Sinclair 1996; Renwick 1998; Marques and Rao 1999; Renwick and Revell 1999). Renwick (1998) showed a consistent relation between the El NiñoSouthern Oscillation (ENSO) cycle and blocking frequency in the Southeast Pacific. He found an increase of blocking activity during the warm phase of ENSO, especially from September to February, during the peak of the ENSO signal. Motivated by this result, Renwick and Revell (1999) examined the possibility of blocking events in the Southeast Pacific be associated with planetary Rossby wave propagation 

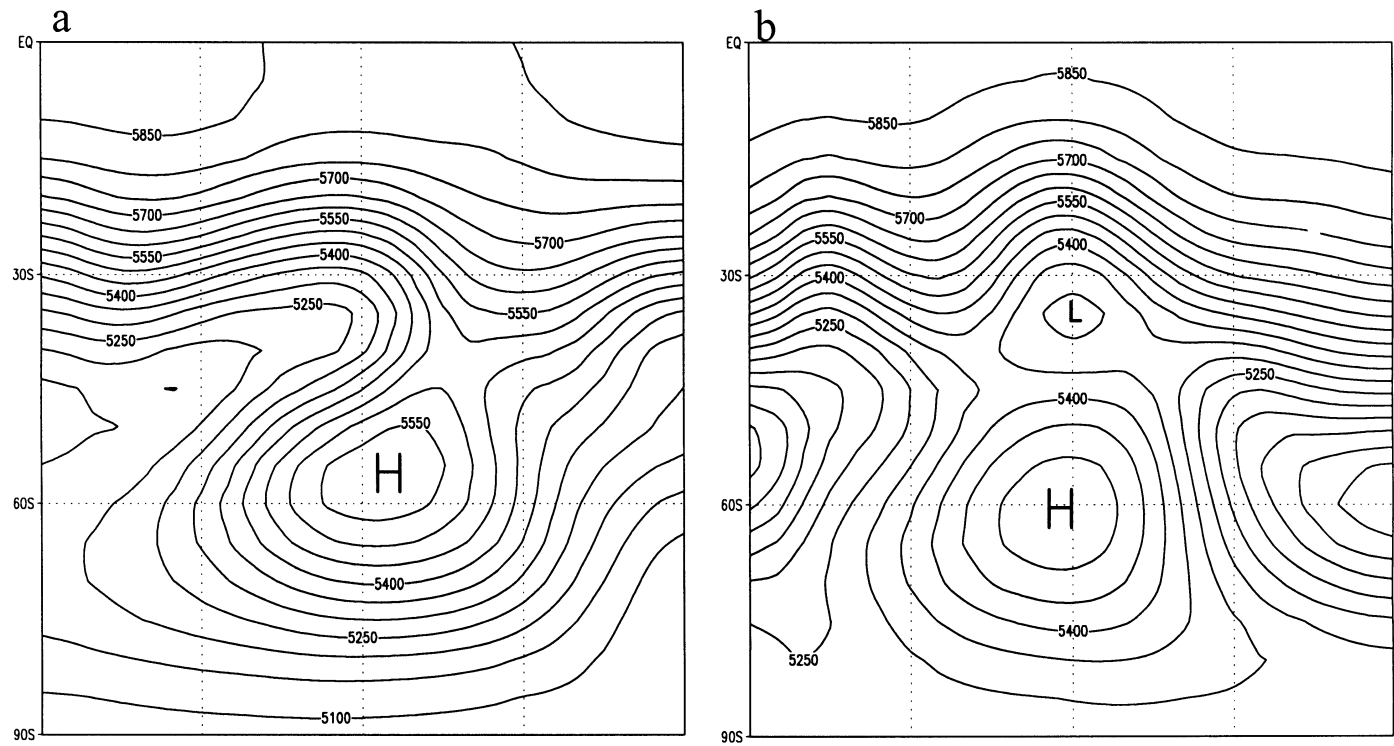

Fig. 1. Idealized sketch of typical $500 \mathrm{hPa}$ geopotential height fields for the Southern Hemisphere in the presence of blocking systems: (a) (inverted) omega pattern, (b) dipole pattern. (The longitudinal extension is typically around $60^{\circ}$ ).

forced by anomalous tropical convection in the equatorial Pacific. Their work was based on a 39-year record of 500-hPa geopotential heights, numerical simulations with a barotropic model, and the linear theory for Rossby wave propagation (Hoskins and Ambrizzi 1993). They showed that the frequency with which blocking events occur over the Southeast Pacific can be understood, at least in part, as a (linear) response to a tropical Rossby wave source represented by anomalous tropical convection traveling eastwards along the Equatorial Pacific ${ }^{1}$.

Marques and Rao (1999), studying a longlasting blocking episode over the Southeast Pacific, indicated that transient eddies contributed to the maintenance of the subtropical and sub-polar branches of the jet through the conversion of eddy kinetic energy into zonal kinetic energy to the north and south of the blocking anticyclone. Conversely, zonal kinetic energy was converted into eddy kinetic energy within the split jet, weakening the zonal flow in this sector (i.e., maintaining the block).

1 However, Renwick and Revell (1999) pointed out that the prediction of individual blocking events should take into account other factors, such as non-linear interactions with transients embedded in the mean flow.
The studies above indicate that a significantly wide spectrum of atmospheric processes affect and, in turn, are affected by blocked flows, and stress the need for analyzing the interaction of blocking with distinct scales of motion. In fact, as argued by Lupo and Smith (1995) and Lupo and Bosart (1999), only by scrutinizing mechanisms acting in both planetary and synoptic-scales, it is possible to describe adequately the life cycle of specific cases of blocking episodes.

The present investigation is motivated by the need of a better understanding of the interaction between blocking evolution and the planetary atmospheric flow in the Southern Hemisphere ( $\mathrm{SH})$, this motivation being based on the following points:

(i) Atmospheric blocking represents a largescale disturbance in the dynamical configuration of the atmosphere, especially in the subtropics and mid-latitudes. It obstructs the normal passage of smaller scale baroclinic systems and deflects the main axis of the subtropical jet stream from its normal position (Coughlan 1983), as sketched in Fig. 1 for the SH.

(ii) Many characteristics of the low-frequency variability of the atmosphere can, to a good extent, be understood by studying barotropic 
Rossby wave propagation on the sphere. From this approach-known as the linear theory for external Rossby wave dispersion-it is shown that the configuration of the large scale atmospheric flow is an important mechanism in driving the dispersion of stationary Rossby waves (Hoskins et al. 1977; Branstator 1983; Borges and Sardeshmukh 1995). In particular, upper level jet streams play an important role acting as waveguides for the Rossby waves (Hoskins and Ambrizzi 1993). For the SH, there is observational evidence that supports this last point (Berbery et al. 1992; Ambrizzi et al. 1995, hereafter referred to as AHH95).

Since blocking modifies the configuration of the large-scale flow, it is reasonable to expect that barotropic Rossby wave propagationwhich, in turn, plays an essential role in the low frequency variability of the atmospherecould experience considerable alterations during the life cycle of the blocking pattern. Given these points, the main objective of the present study is to identify propagation patterns that characterize modifications on the behavior of Rossby wave dispersion during the evolution of blocking systems in the SH. The approach employed in this investigation consists of a numerical analysis of the propagation of external Rossby modes in $\mathrm{SH}$ wintertime flows during periods of blocking activity and the adjacent weeks (i.e., the weeks immediately prior to the onset and after the decay of the blocking system).

The main difference between the present investigation and the one by Renwick and Revell (1999) is that we are primarily interested in the influence of blocking systems over the planetary Rossby wave propagation in the SH (specifically over the Pacific Ocean). Renwick and Revell (1999), instead, studied the influence of planetary Rossby waves in the modulation of the frequency with which blocking events are observed in the South Pacific, and its relation to anomalous tropical convection. Nevertheless, some of our results show that planetary Rossby waves may play some role in the initiation of the blocking events studied here.

This paper is organized as follows: Section 2 describes the selected blocking episodes and the data source, while Section 3 briefly describes the barotropic model. The numerical results and a detailed discussion on the Rossby wave propagation during periods with, and without blocking, are presented in Section 4 . Section 5 contains the concluding remarks.

\section{Description of the blocking episodes and data source}

Two blocking events observed over distinct longitudes on the South Pacific during the austral winter of 1995 were selected, as well as atmospheric flows from the previous and subsequent seven-day periods, in order to generate the blocking, and pre- and post-blocking basic states for the barotropic model. The blocking periods, selected from the National Centers for Environmental Prediction/National Center for Atmospheric Research Reanalysis Project data, are: 5 to 10 July 1995 (denoted Blocking 1, or BL1), and 21 to 26 August 1995 (denoted Blocking 2 , or BL2). The respective previous and subsequent weeks are: 28 June to 4 July 1995 (preBlocking 1, or PRE-BL1), 11 to 17 July 1995 (post-Blocking 1, or POST-BL1), and 14 to 20 August 1995 (pre-Blocking 2, PRE-BL2), 27 August to 2 September 1995 (post-Blocking 2, POST-BL2). For convenience, Table 1 summarizes the selected cases and the nomenclature to be used henceforth. The large scale flow configuration for these periods is shown on Figures $2(\mathrm{a}-\mathrm{c})$ and $3(\mathrm{a}-\mathrm{c})$, and will be discussed later in this section.

Note that the periods with blocked flows are relatively short ( 6 days), but still above the fiveday threshold commonly used to characterize blocking in the SH (Trenberth and Mo 1985; Sinclair 1996). The objective method used to identify the blocked flows, and to determine the dates of onset and dissipation of the blocking systems, was the index originally proposed by Lejenäs and Økland (1983) and modified by Tibaldi and Molteni (1990) (adapted for SH latitudes by Tibaldi et al. 1994), defined as geopotential height gradients (GHG) given by:

$$
\begin{aligned}
\text { GHGS } & =\frac{Z\left(\Phi_{S}\right)-Z\left(\Phi_{0}\right)}{\left(\Phi_{S}-\Phi_{0}\right)}, \\
\text { GHGN } & =\frac{Z\left(\Phi_{0}\right)-Z\left(\Phi_{N}\right)}{\left(\Phi_{0}-\Phi_{N}\right)},
\end{aligned}
$$

where $Z$ is the geopotential height at $500 \mathrm{hPa}$, and $\Phi_{N}=35^{\circ} \mathrm{S}+\Delta, \quad \Phi_{0}=50^{\circ} \mathrm{S}+\Delta$, $\Phi_{S}=65^{\circ} \mathrm{S}+\Delta$, with $\Delta=-3.75^{\circ}, 0^{\circ},+3.75^{\circ}$. 
Table 1. Nomenclature adopted for the blocking, and pre- and post-blocking periods, selected from the austral winter of 1995 .

\begin{tabular}{|c|c|c|c|}
\hline & pre-Blocking (PRE-BL) & Blocking (BL) & post-Blocking (POST-BL) \\
\hline 1 & $\begin{array}{l}\text { 28 June to } 4 \text { July } 1995 \\
\text { (PRE-BL1) }\end{array}$ & $\begin{array}{l}5 \text { to } 10 \text { July } 1995 \\
\text { (BL1) }\end{array}$ & $\begin{array}{l}11 \text { to } 17 \text { July } 1995 \\
\text { (POST-BL1) }\end{array}$ \\
\hline 2 & $\begin{array}{l}14 \text { to } 20 \text { August } 1995 \\
\text { (PRE-BL2) }\end{array}$ & $\begin{array}{l}21 \text { to } 26 \text { August } 1995 \\
\text { (BL2) }\end{array}$ & $\begin{array}{c}27 \text { August to } 2 \text { September } 1995 \\
\text { (POST-BL2) }\end{array}$ \\
\hline
\end{tabular}

Following Tibaldi et al. (1994), the flow in a given longitude was considered blocked when the conditions below were satisfied simultaneously for at least one value of $\Delta$ :

$$
\begin{aligned}
& \text { GHGN }>0.0, \\
& \text { GHGS }<-10 \mathrm{~m} /{ }^{\circ} \text { latitude, }
\end{aligned}
$$

Once the blocking episodes were selected, the periods of seven days before the onset and seven days after the decay of the blocked flows were used to derive the non-blocking basic states. The periods of seven days prior and subsequent to the systems were chosen so that they would have approximately the same length of the blocking events. Analyzing the wave dispersion in the sequence pre-blocking/blocking/ post-blocking can highlight possible impacts of the presence of the blocking patterns on the Rossby wave propagation. In Section 3 we discuss in more details how the basic states were generated.

Figures 2 and 3 depict the average $250 \mathrm{hPa}$ wind speeds, and $500 \mathrm{hPa}$ geopotential height fields over the South Pacific for the periods defined above. To the end of this section the term 'zonal index' will be used referring to the strength of the zonal flow (as in Willet 1949), and should not be confused with the objective index indicated in (1).

From Fig. 2a (PRE-BL1) we observe that, before the establishment of a blocking, the circulation was remarkably zonal and the subtropical jet had its core to the east of the Australian coast. During the blocking period BL1 (Fig. 2b), the main position of the subtropical jet streak was farther east, along the equatorial flank of the blocking system. Since an average is being taken, Fig. 2b does not show a clear blocking system, but it is possible to identify the ridge along $60^{\circ} \mathrm{S}$ associated with the blocking anticyclone. In the mature stage of this system a classic dipole pattern (not shown) was observed, resembling the idealized depiction on Fig. 1b. During its life cycle the blocking moved from $160^{\circ} \mathrm{W}$ (east of New Zealand) to $120^{\circ} \mathrm{W}$ along approximately $55^{\circ} \mathrm{S}$. The longitudinal sector where this system developed is recognized in the literature as a favorable region for the formation of blocking during the $\mathrm{SH}$ winter (Trenberth and Mo 1985).

Figure 2c shows the configuration of the mean flow for the week following BL1. The geopotential height indicates, for Central South Pacific, a similar pattern to that seen during the blocking period. This occurred because shortly after the decaying of BL1, a new blocked pattern started to develop. However, it lasted less than two days and dissipated before the end of the POST-BL1 period, so that the criterion of longevity could not be satisfied. One can note that, for POST-BL1, the main subtropical jet streak decreased its zonal extension and moved southwestwards (to southern Australia) with respect to the previous week. The subpolar jet is also evident in the POST-BL1 period.

The geopotential height at $500 \mathrm{hPa}$, and mean wind speeds at $250 \mathrm{hPa}$ for the period PRE-BL2, are shown in Fig. 3a. The geopotential height field reveals a zonal index that is stronger than the one observed for PRE-BL1 (Fig. 2a), especially along $60^{\circ} \mathrm{S}$. The upper-level wind field also exhibits distinct zonal asymmetries, with three main subtropical jet streaks: south of 

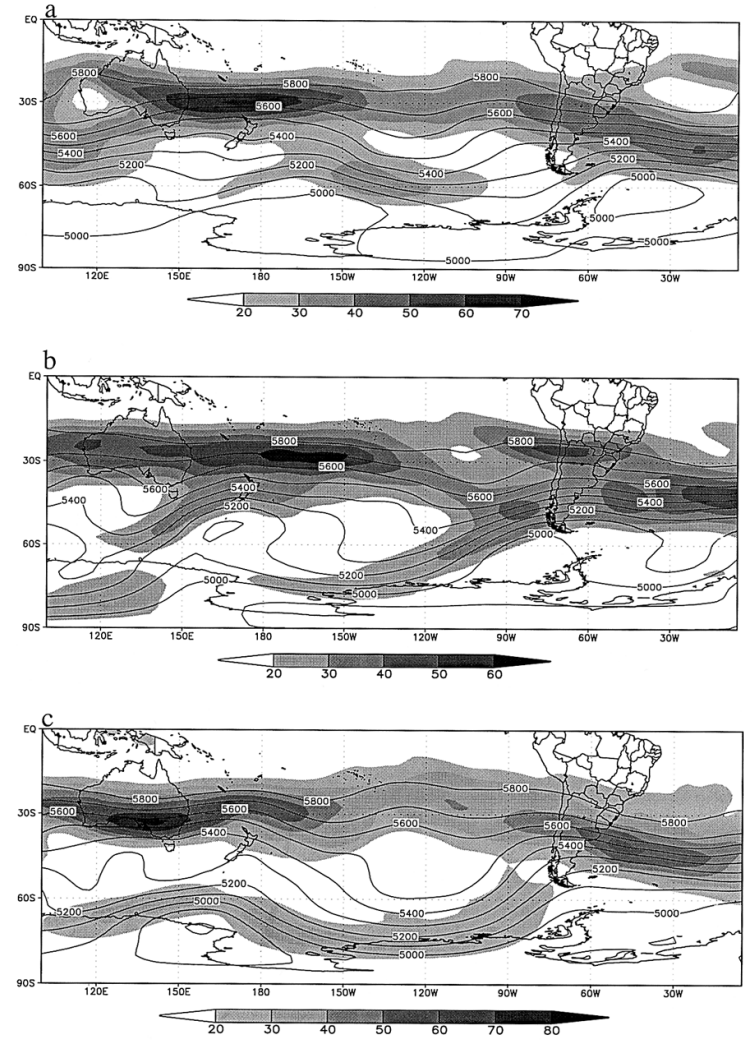

Fig. 2. Mean wind speeds at $250 \mathrm{hPa}$ $\left(\mathrm{m} \mathrm{s}^{-1}\right)$, and mean geopotential heights at $500 \mathrm{hPa}$ for the South Pacific sector:

(a) 28 June to 4 July 1995 (PRE-BL1),

(b) 5 to 10 July 1995 (BL1), (c) 11 to 17 July 1995 (POST-BL1). Only westerly flows stronger than $20 \mathrm{~m} \mathrm{~s}^{-1}$ are shown.

Australia (most intense core), Central South Pacific and to the east of the South American coast. It is also possible to observe the polar jet between $150^{\circ} \mathrm{E}$ and $50^{\circ} \mathrm{W}$.

During the period BL2 (Fig. 3b), a blocking anticyclone developed between $110^{\circ} \mathrm{W}$ and $80^{\circ} \mathrm{W}$ along the latitude of $55^{\circ} \mathrm{S}$ (southwest of South America). This system displayed a slower displacement when compared with BL1 and, during its entire life cycle, resembled the sketch depicted on Fig. 1a. The subtropical jet shows an elongated core, meandering from $180^{\circ} \mathrm{W}$ to the coast of Chile, away from its climatological position. For the period POST-BL2 (Fig. 3c), a geopotential height field with considerable meridional component is still noticeable along the subtropical sector, characterizing an intermediate pattern between the high zonal index
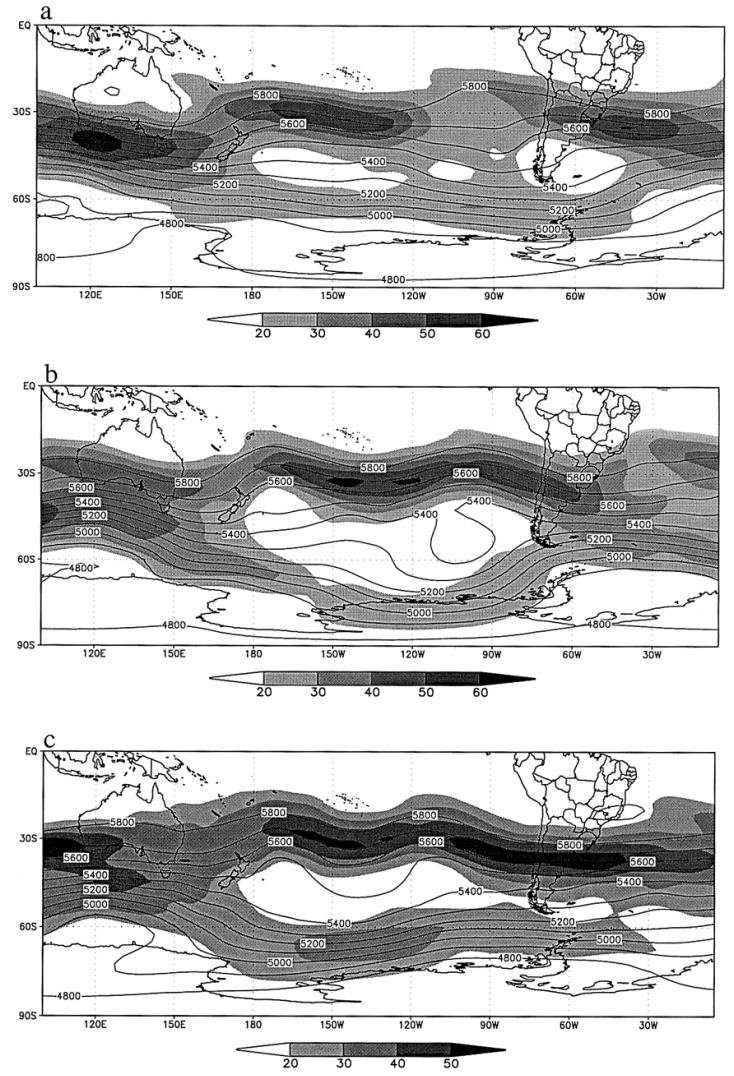

Fig. 3. Same as Fig. 2, but for the periods: (a) 14 to 20 August 1995 (PREBL2), (b) 21 to 26 August 1995 (BL2), (c) 27 August to 2 September 1995 (POST-BL2).

flow of PRE-BL2, and the blocked flow BL2. The subtropical jet did not return to its climatological position, meandering from northeast of New Zealand to the South American coast. The sub-polar jet is also intense between $170^{\circ} \mathrm{W}$ and $110^{\circ} \mathrm{W}$, along $65^{\circ} \mathrm{S}$.

Although the fields for POST-BL1 and POSTBL2 still show features with significant meridional components, the blocking systems could not be characterized anymore-neither visually nor using the objective blocking index proposed by Tibaldi et al. (1994). For this reason these periods were unambiguously classified as postblocking.

\section{Model description and methodology}

\subsection{The barotropic model and the forcing}

The barotropic model used in this study is based on the damped barotropic vorticity equa- 
tion $(B V E)$ :

$$
\left(\frac{\partial}{\partial t}+\overrightarrow{\mathbf{V}}_{\boldsymbol{\Psi}} \cdot \vec{\nabla}\right) \zeta=-\frac{\xi}{\tau}-\lambda \nabla^{6} \boldsymbol{\xi}+\overline{\mathbf{F}}+\mathbf{F}^{\prime} .
$$

Here, $\zeta$ and $\xi$ are the absolute and relative vorticity, respectively, and the overbars (primes) refer to basic state (perturbation) quantities. This equation is solved using the spectral transform technique, with a truncation T21. The first term on the right-hand side is a Newtonian damping with timescale $\tau=5$ days, and the second term is a hyperdiffusion with coefficient $\lambda=2.338 \times 10^{16} \mathrm{~m}^{4} \mathrm{~s}^{-1}$ acting on a timescale of 4 days on the smallest length scale resolved by the model. It is important to emphasize that we use a strong Newtonian damping in order to suppress (or, at least, significantly reduce) the growth of modes by pure barotropic instability of the background flow.

The basic state forcing $\overline{\boldsymbol{F}}$ is determined in such a way that the specified basic state is an exact solution of (2) with $F^{\prime}=0$. The perturbation forcing $F^{\prime}$ is given by:

$$
\mathbf{F}^{\prime}=-\nabla \cdot\left(\bar{\zeta} \mathbf{V}_{\chi}^{\prime}\right)-\nabla \cdot\left(\zeta^{\prime} \overline{\mathbf{V}}_{\chi}\right),
$$

and is switched on at $t=0$. Note that the forcing includes the advection of perturbation vorticity by the divergent component of the flow, so that the present model is equivalent to the wavy-linear-C model in Sardeshmukh and Hoskins (1988). This implies that the model is able to represent extratropical stationary Rossby waves that are triggered even with an equatorial forcing.

In the first set of numerical experiments, the perturbation forcing (hereafter, referred to as 'forcing') is represented by a circular shaped divergence anomaly with $15^{\circ}$ of radius positioned on a subtropical latitude $-20^{\circ} \mathrm{S}, 40^{\circ} \mathrm{E}$, as in AHH95-and is interpreted purely as a wave maker. The anomaly has a maximum magnitude of $3 \cdot 10^{-6} \mathrm{~s}^{-1}$ at the center of the circle, and decays radially with the square of the cosine of the distance in degrees.

In the second set of experiments the forcing is employed as a proxy representing the effect of tropical convection in the upper levels of the troposphere (i.e., upper-level divergence). For this case, anomalies of outgoing longwave radiation (OLR) are used as indicators of convective activity in the tropics (Julian 1984; Krishnamurti and Low-Nam 1986). The position and shape (circular or elliptical) of the forcing are based on the analysis of OLR anomalies during the periods (PRE-BL1) $+($ BL1 $)+($ POST-BL1) and (PRE-BL2) + (BL2) + (POST-BL2) with respect to the July and August climatology for the 1979-1994 period, respectively. For each of the two periods (i.e., (PRE-BL1) $+($ BL1) + (POSTBL1) and (PRE-BL2) + (BL2) + (POST-BL2)), the most outstanding OLR anomaly on the tropical belt was selected to determine the shape and position of the forcing to be applied on the three corresponding cases. In other words, the same tropical forcing is used for the PREBL1, BL1 and POST-BL1 periods, the same being true for PRE-BL2, BL2 and POST-BL2 periods.

Figure 4a shows, for the entire tropical belt, negative anomalies of OLR referring to the period (PRE-BL1) $+($ BL1 $)+($ POST-BL1), and Fig. $4 \mathrm{~b}$ displays the convective pattern selected to indicate the position $\left(0^{\circ}, 95^{\circ} \mathrm{E}\right)$ and shape (elliptical, with eccentricity 0.3 ) of the forcing to be used on the three corresponding cases. Figures $4 \mathrm{c}$ and $4 \mathrm{~d}$ are analogous to $4 \mathrm{a}$ and $4 \mathrm{~b}$, but for the period (PRE-BL2) + (BL2) + (POSTBL2). For this case the forcing has a circular shape, with a radius of $15^{\circ}$ and is positioned at $10^{\circ} \mathrm{N}, 75^{\circ} \mathrm{E}$. An anomaly with stronger magnitude is used on all experiments with tropical forcing: $5 \cdot 10^{-6} \mathrm{~s}^{-1}$.

It should be stressed that the representation of tropical convection in all its detailed structure (e.g., areas of compensating subsidence represented by areas of upper level convergence; Grimm and Silva Dias 1995) is not a main issue in this investigation. The use of the OLR fields is, essentially, an approach chosen to avoid complete arbitrariness when positioning the tropical forcing. Thus, from a purely observational standpoint, the results obtained here may not match exactly the planetary Rossby wave propagation pattern observed during the specific blocking events studied, but can highlight the general characteristics of the impact of blocking systems on such propagation.

The six distinct basic states for the periods indicated in Section 2 are generated from the corresponding $250 \mathrm{hPa}$ zonally asymmetric flows. Many previous studies employing barotropic models have applied this level, which seems to best represent both the equivalent barotropic level at midlatitudes and the level 

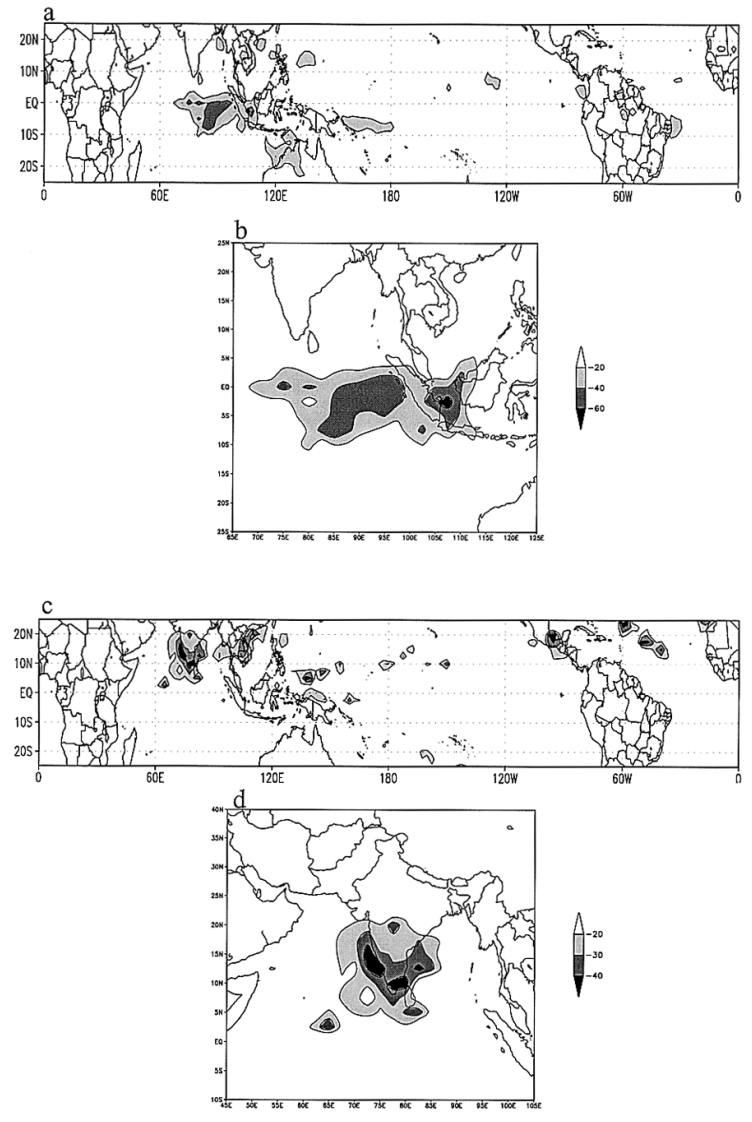

Fig. 4. Negative anomalies in outgoing longwave radiation $\left(\mathrm{W} \mathrm{m}^{-2}\right)$ : (a) and (b) refer to the period 28 June to 17 July 1995, and (c) and (d) to the period 14 August to 2 September 1995. (a) and (c) indicate the corresponding anomalies for the entire tropical belt. (b) [(d)] shows the convective pattern chosen to represent the tropical forcing on situations PRE-BL1 [PRE-BL2], BL1 [BL2] and POST-BL1 [POST-BL2].

of strongest tropical divergence (Hoskins and Karoly 1981; Borges and Sardeshmukh 1995).

\subsection{Hoskins filter}

Despite some limitations when applied to a zonally asymmetric flow, the linear theory of Rossby wave propagation has been successfully used to explain many features associated with atmospheric teleconnection patterns (Hoskins and Ambrizzi 1993). An important assumption considered in this theory is that the basic state evolves slowly compared with the spaceand time-scales of the perturbation (in other words, the WKB or Liouville-Green approximation must hold), such that:

$$
\left(\frac{\partial \bar{\xi}}{\partial t}\right) \ll\left(\frac{\partial \xi^{\prime}}{\partial t}\right) .
$$

The ideal situation is when the basic state flow does not display fine structures in the zonal and meridional directions that are associated with high frequency processes in the atmosphere. For basic state flows generated from sufficiently long time averaging (such as seasonal and annual averages) only lower frequency features are kept. Thus, such basic states tend to evolve very slowly compared with the timescale of the perturbations, allowing the omission of the term $(\partial \bar{\xi} / \partial t)$ when linearizing the BVE. For these cases, the WKB approximation is satisfied, at least approximately, and the analysis of the Rossby wave propagation using the linear wave theory is possible (Hoskins and Karoly 1981; Branstator 1983; Karoly 1983a; Hoskins and Ambrizzi 1993, AHH95).

However, since the duration of a typical blocking pattern in the $\mathrm{SH}$ is considerably short (5 to 10 days; Trenberth and Mo 1985; Tibaldi et al. 1994), we use basic states corresponding to very short time periods (6 and 7 days). In this case, high frequency processes in the basic state flow are not adequately eliminated by the time averaging alone. To solve this problem, a smoothing function was applied to the zonal and meridional components of the basic state wind in order to damp the high frequency processes after applying the time averaging and truncating the spectral expansion at the wave number 21. This was accomplished with the use of the Hoskins spectral filter (Hoskins 1980; Sardeshmukh and Hoskins 1984).

The Hoskins filter acts across the whole spectrum, but damps more effectively the higher wavenumbers on the model truncation (Sardeshmukh and Hoskins 1984). The Hoskins filter $S_{n}$ applied to a wavenumber $n$ is represented by:

$$
\mathbf{S}_{\mathbf{n}}=\exp \left\{-\boldsymbol{\Gamma}[\mathbf{n}(\mathbf{n}+1)]^{2}\right\},
$$

where $\Gamma$ (a non dimensional quantity) depends on the magnitude of the damping desired for the largest wavenumber $N$, which represents the model truncation. The values assumed by $S_{n}$ obey the following criterion: 


$$
S_{n}=\left\{\begin{array}{ll}
S_{0}=1 & \text { for } n=0 \\
1>S_{n}>S_{N} & \text { for } N>n>0 \\
S_{N} \ll S_{0} & \text { for } n=N
\end{array}\right\}
$$

The spectral coefficients were multiplied by the corresponding values of $S_{n}$ for the smoothing. Figure 2 from Sardeshmukh and Hoskins (1984) exemplifies the use of this filter when applied to a T24 truncation (i.e., for $N=24$ ). For wavenumbers smaller than or equal to 5 , the damping is less intense, becoming more effective for wavenumbers equal to or greater than 10. This is important to keep the blocking 'signature' in the basic state field, since these systems are usually associated with a wavenumber 3 or 4 (Trenberth and Mo 1985).

After several sensitivity tests, the value of $\Gamma$ chosen for the present investigation was $1.4035 \cdot 10^{-5}$, leading to a value of 0.05 for $S_{n}$ at $n=21$ (i.e., the amplitude of the wave associated with wavenumber 21 is damped by $95 \%$ ). Therefore, the use of spectral filter on the basic state and the linear damping applied over the perturbations (see equation (1)), ensured the attainment of stationary solutions for all numerical experiments to be presented in the next section.

\subsection{Stationary wavenumber and the wave activity flux}

A useful diagnostic tool for representing the mean background state is the calculation of the stationary Rossby wavenumber $K_{S}$ which, using a Mercator projection over the sphere, is given by:

$\mathbf{K}_{\mathbf{S}}=\left\{\left[2 \Omega-\left(\frac{1}{\cos \phi} \frac{\partial}{\partial \phi}\right)^{2}\left(\cos ^{2} \phi \overline{\mathbf{v}}\right)\right] \frac{1}{\overline{\mathbf{v}}}\right\}^{1 / 2} \cos \phi$,

where $\Omega$ is the angular speed of rotation of the earth, $\phi$ is the latitude and $\bar{v}=\overline{\mathbf{u}} / \mathbf{a} \cos \phi$ (where $a$ is the earth's radius). $K_{S}$ is the total wavenumber for which a barotropic Rossby wave is stationary at a particular location in a given background zonal flow. Branstator (1983) and Hoskins and Ambrizzi (1993) showed that the distribution of $K_{S}$ can be used to infer the location of critical lines and waveguides for stationary Rossby waves. For example, zonally oriented regions of relatively high values of $K_{S}$ bounded by lower values of $K_{S}$ to the north and to the south (usually associated with strong jet streams) indicate sectors favorable for ducting Rossby waves. Here, $K_{S}$ is used to give a qualitative picture of the basic state flow, and allows a first assessment of the impact of blocking systems on the dynamical structure relevant for the Rossby wave dispersion.

Another approach applied in this study is the analysis of the wave activity flux, as originally defined by Plumb (1986). In order to better understand the transient eddy propagation on a slowly varying time-mean flow, Plumb (1986) defined the vector quantity $\boldsymbol{M}_{T}$ which is a conservable measure of the flux of eddy activity (for small amplitude transients) and which is parallel to group velocity for a quasi-plane wave train. Nakamura (1994) and Naoe et al. (1997) have shown the applicability of Plumb's approach on a barotropic atmosphere as well.

The computation of the $\boldsymbol{M}_{T}$ vector was done for all numerical experiments to be shown in the next section. Following Naoe et al. (1997), $\boldsymbol{M}_{T}$ is defined as:

$$
\mathbf{M}_{T}=\mathbf{M}_{R}+\overline{\mathbf{U}} M
$$

where $\overline{\mathbf{U}}$ is the basic state flow and $M$ is the density of wave activity (Plumb 1986), given by:

$$
\mathbf{M}=\frac{\mathbf{p e} \cos \phi}{\left\|\nabla_{H} \bar{\zeta}\right\|},
$$

where $p$ is a constant $(250 \mathrm{hPa} / 1000 \mathrm{hPa}), e$ is the eddy enstrophy $\left(=\frac{1}{2} \zeta^{\prime 2}\right), \phi$ is the latitude and $\left\|\nabla_{H} \bar{\zeta}\right\|$ is the absolute value of the gradient of the basic state absolute vorticity. $\boldsymbol{M}_{R}$ in eq. (8) is, in turn, given by:

$$
\mathbf{M}_{R i}=\mathbf{n}_{j} \mathbf{B}_{j i},
$$

where $n$ is a unit vector on the direction of the gradient of the basic state absolute vorticity and the scalar $B_{j i}$ is:

$$
B=\left[\begin{array}{cc}
\overline{u^{\prime} v^{\prime}} & \overline{\left(v^{\prime 2}-u^{\prime 2}\right) / 2} \\
\overline{\left(v^{\prime 2}-u^{\prime 2}\right) / 2} & -\overline{u^{\prime} v^{\prime}}
\end{array}\right] .
$$

The overbars in (11) refer to the time mean of the perturbed quantities indicated. The perturbations are obtained through the model integration.

It is very important to stress that some recent studies (Takaya and Nakamura 1997, 2001), have proposed a new formulation of 
an approximate conservation relation of waveactivity pseudomomentum, which is applicable for either stationary or migratory quasigeostrophic eddies on a zonally varying basic flow.

In the present study, we will assume that the time average of the basic state and the filter applied to it are sufficient to guarantee that the disturbances are slowly modulated in the WKB sense. However, in view of this recent formulation of the wave activity, the results to be shown in the next section have to be seen with the limitation of the methodology used in our analysis.

\section{Results}

\subsection{Spatial configuration of the stationary wavenumber}

Figures 5 and 6 depict $K_{S}$ fields for the six situations studied. Zonal bands of high values of $K_{S}$, bounded by lower values to the north and to the south, are typically associated with jetlike flows. In fact, analyzing the Pacific Ocean sector in Figs. 5a, b, c and Figs. 6a, b, c in comparison with Figs. 2 and 3 , respectively, it is possible to note a good agreement between the subtropical jet streaks and the local maxima in $K_{S}$ (with values above 6 ). On the other hand, the equatorial belt is dominated by a sector where wave propagation is inhibited due to the presence of the easterlies (critical latitudes). On Figs. 5 and 6 these bands are represented by regions of high values of $K_{S}$ (values above 12), with latitudinal borders indicated by thick contours.

It is interesting to notice that the configurations for BL1 (Fig. 5b) and BL2 (Fig. 6b) show that the values of $K_{S}$ at sub-polar latitudes in the Pacific sector are, on average, higher than for the non-blocking counterparts (Figs. 5a, c and 6a, c). This feature is more evident when we analyze the meridional profiles of $K_{S}$ between $85^{\circ} \mathrm{S}$ and $30^{\circ} \mathrm{N}$ within the longitudinal sector ranging from $120^{\circ} \mathrm{E}$ to $60^{\circ} \mathrm{W}$ for BL1 (Figs. 7a, b, c), and $150^{\circ} \mathrm{E}$ and $30^{\circ} \mathrm{W}$ for BL2 (Figs. 7d, e, f) (in both cases the blocking pattern is positioned at the middle of the longitudinal belt).

Note that, for all the $K_{S}$ profiles (Fig. $7 \mathrm{a}-\mathrm{f}$ ), two latitudinal sectors display maximum values in $K_{S}$ in the $\mathrm{SH}$ : one at the subtropical latitudes, and the other in the middle latitudes, which are associated with the subtropical and
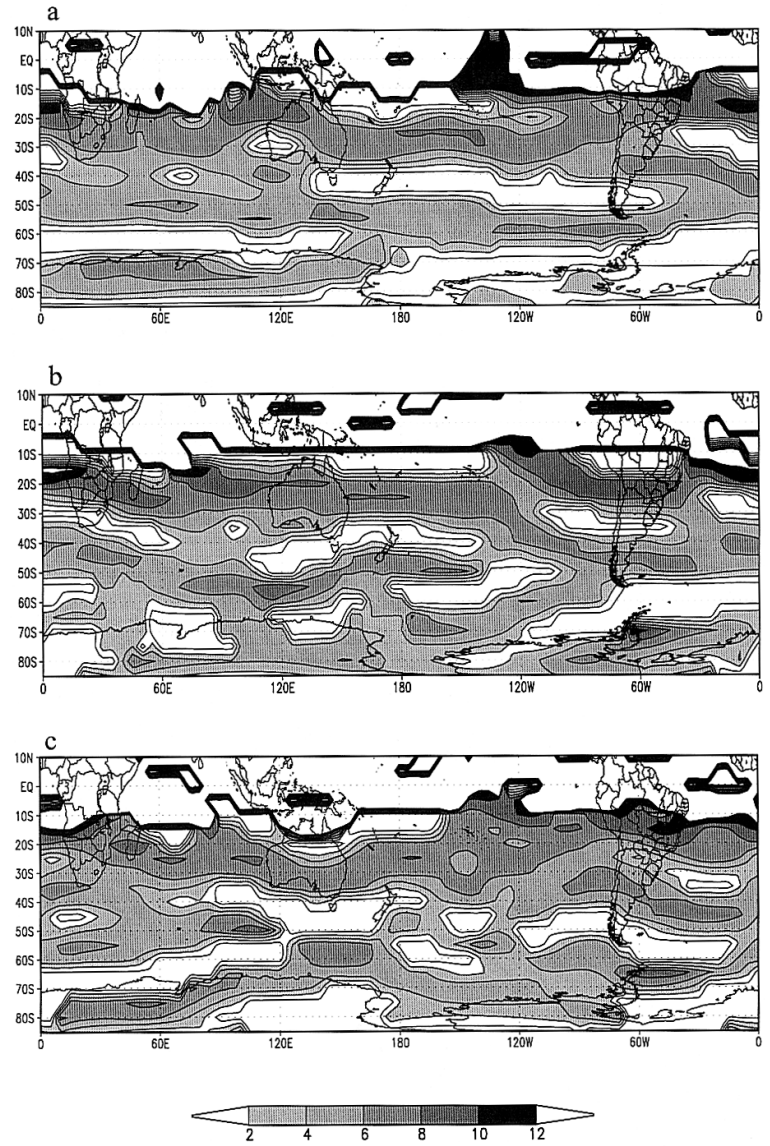

Fig. 5. Stationary wavenumber $\left(K_{S}\right)$ (as defined in Eq. (7)) between $85^{\circ} \mathrm{S}$ and $30^{\circ} \mathrm{N}$ : (a) PRE-BL1, (b) BL1, (c) POSTBL1. Regions where the meridional gradient of the absolute vorticity $\left(\beta^{*}=\partial f / \partial y-\partial^{2} \bar{u} / \partial y^{2}\right)$ is less than zero, or where the flow is dominated by the easterlies, are not shaded.

sub-polar jets, respectively. As discussed in AHH95, these regions can act as waveguides for the Rossby wave propagation. For BL1 (Fig. 7b), and BL2 (Fig. 7e) the two maxima are displaced slightly to the north when compared with the periods without blocking. In fact, for the non-blocking periods (Figs. 7a, c and 7d,f) the meridional profile of $K_{S}$ at higher latitudes agree very well with those shown by Karoly (1983a) based on climatological basic states, with $K_{S}$ values gradually approaching zero.

Nevertheless, by examining the profiles of $K_{S}$ at high latitudes during the blocking episodes (Figs. $7 \mathrm{~b}$ and $7 \mathrm{e}$ ), it is possible to identify a 

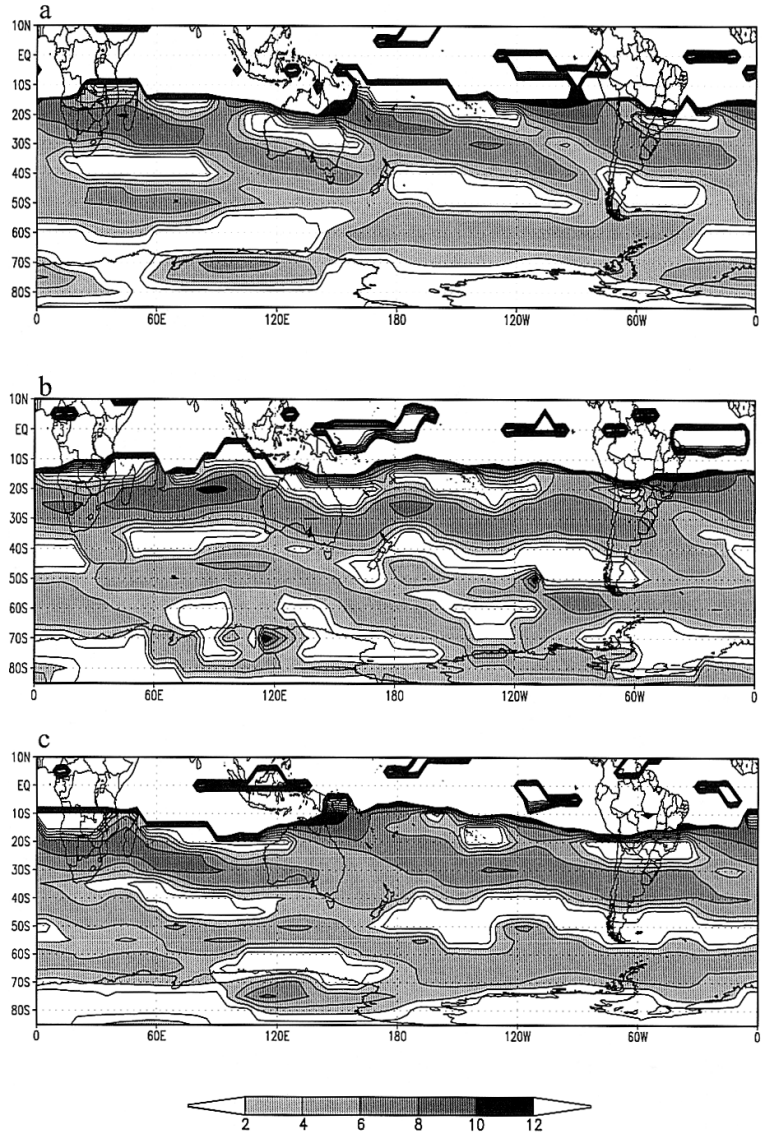

Fig. 6. Same as Fig. 5, but for: (a) PREBL2, (b) BL2, (c) POST-BL2.

slight increase on the stationary wavenumber. Note that the mean values of $K_{S}$ reaching 3 (BL2) and 4 (BL1) on the sub-polar sector are bounded to the north by values around 1 and 2 . Based on linear theory for Rossby wave propagation, this meridional profile suggests that a given wave-train with wavenumbers up to 3 or 4 could propagate into higher latitudes if any discontinuity is present along the belt of minimum $K_{S}$ north of the polar maximum. This possibility is assessed with the numerical approach.

\subsection{Barotropic model results}

Throughout this subsection, Rossby wave dispersion is examined with the aid of the model-generated vorticity anomalies for day 20 of integration, and the corresponding waveactivity fluxes (i.e., the direction and magnitude of the vector $\mathbf{M}_{T}$ ).

\section{a. PRE-BL1, BL1 and POST-BL1 cases: subtropical forcing}

In order to assess how the propagation of Rossby waves along the subtropical jet waveguide is affected by a blocking system, a circular forcing was placed at $20^{\circ} \mathrm{S}, 40^{\circ} \mathrm{E}$, which is the same location used in AHH95 (see their Fig. 12a). Relative vorticity anomalies for the $20^{\text {th }}$ day of model integration for PRE-BL1 period is depicted in Fig. 8a. The stationary wave propagation shows a clear zonal pattern, displaying a wavenumber around 5 with the Rossby wave activity propagating along the Australian jet stream. This result is in agreement with AHH95. Comparing with Figs. 5a and 7a, one can notice a good agreement between the position of the maximum $K_{S}$ at the subtropical South Pacific region and the wave train seen in Fig. 8a. In particular, Fig. 7a indicates that the Rossby waves with wavenumber 5 can be trapped in this region, which is consistent with the numerical result.

The wave activity flux (Fig. 8b) exhibits higher values in the subtropical sector. It is interesting to note that the maximum magnitude of the wave activity $\left(40 \mathrm{~m}^{2} \mathrm{~s}^{-1}\right)$ occurs near the longitudinal sector where, in the following week, the blocking pattern would be established (between $180^{\circ} \mathrm{W}$ and $120^{\circ} \mathrm{W}$ ). This result agrees with those obtained by Nakamura (1994) and Naoe et al. (1997) who, through observational and numerical analyses, suggested the possibility of wave activity flux convergence (associated with barotropic Rossby waves) in the longitudinal zone where the onset of a blocking event is observed.

The Rossby wave propagation corresponding to period BL1 with a subtropical forcing is shown in Fig. 8c. In contrast to Fig. 8a, the amplitude of the wave propagation at higher latitudes is stronger, with wavenumbers around 2 and 3. The propagation obtained for the period BL1 in the subtropical region is much weaker and not distinguishable in the plots. The corresponding wave activity flux (Fig. 8d) shows a more intense activity than during the previous week (PRE-BL1), and indicates that the propagation at higher latitudes was enhanced. It should be emphasized that, from the stationary wavenumber distribution and meridional profile for the BL1 period (Figs. 5b and 7b), it was suggested that the Rossby wave propagation to 

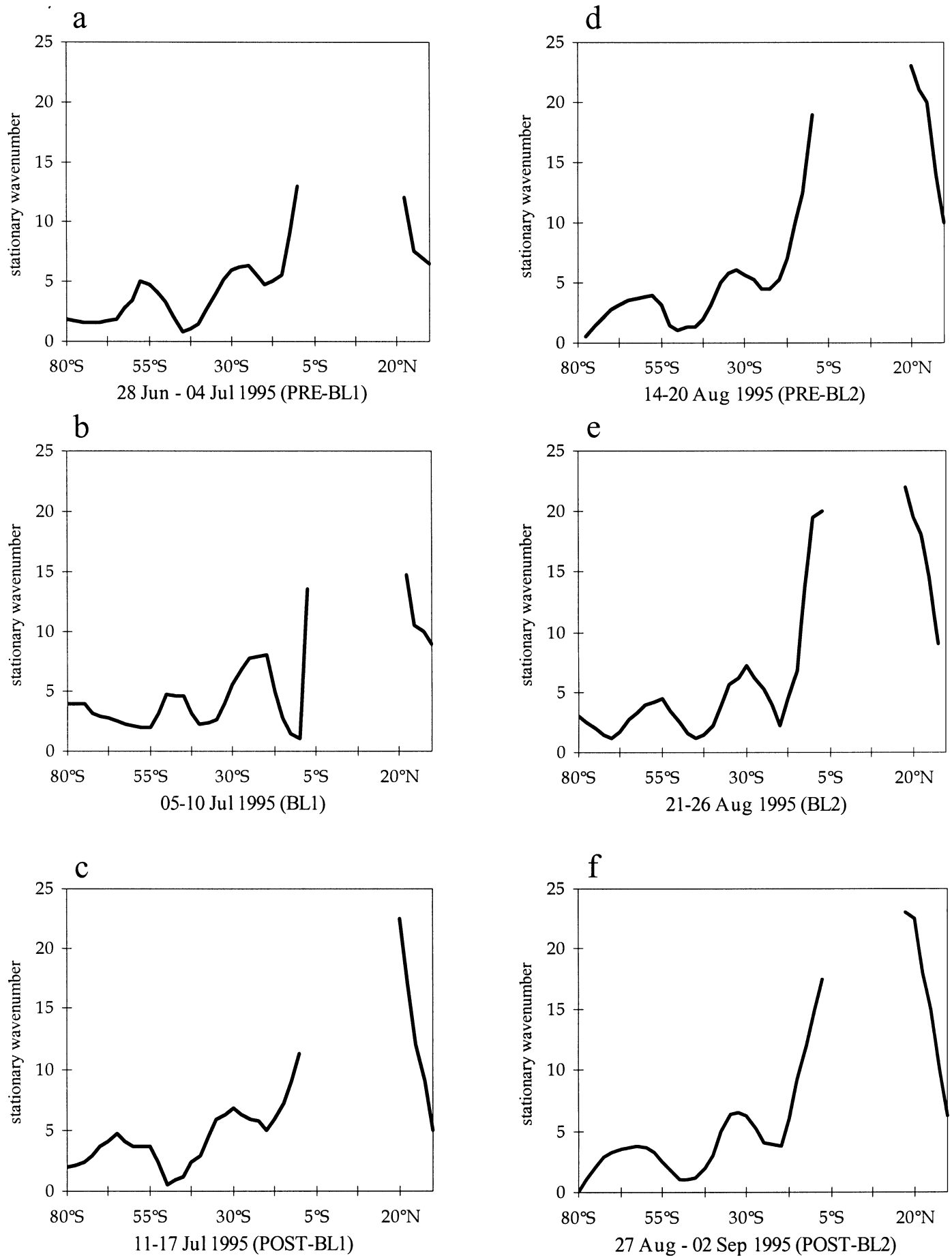

Fig. 7. Meridional profiles from $80^{\circ} \mathrm{S}$ to $30^{\circ} \mathrm{N}$ of the mean stationary wavenumber $\left(K_{S}\right)$ between $120^{\circ} \mathrm{E}$ and $60^{\circ} \mathrm{W}$ : (a) PRE-BL1, (b) BL1, (c) POST-BL1; and between $150^{\circ} \mathrm{E}$ and $30^{\circ} \mathrm{W}$ : (d) PREBL2, (e) BL2, (f) POST-BL2. 

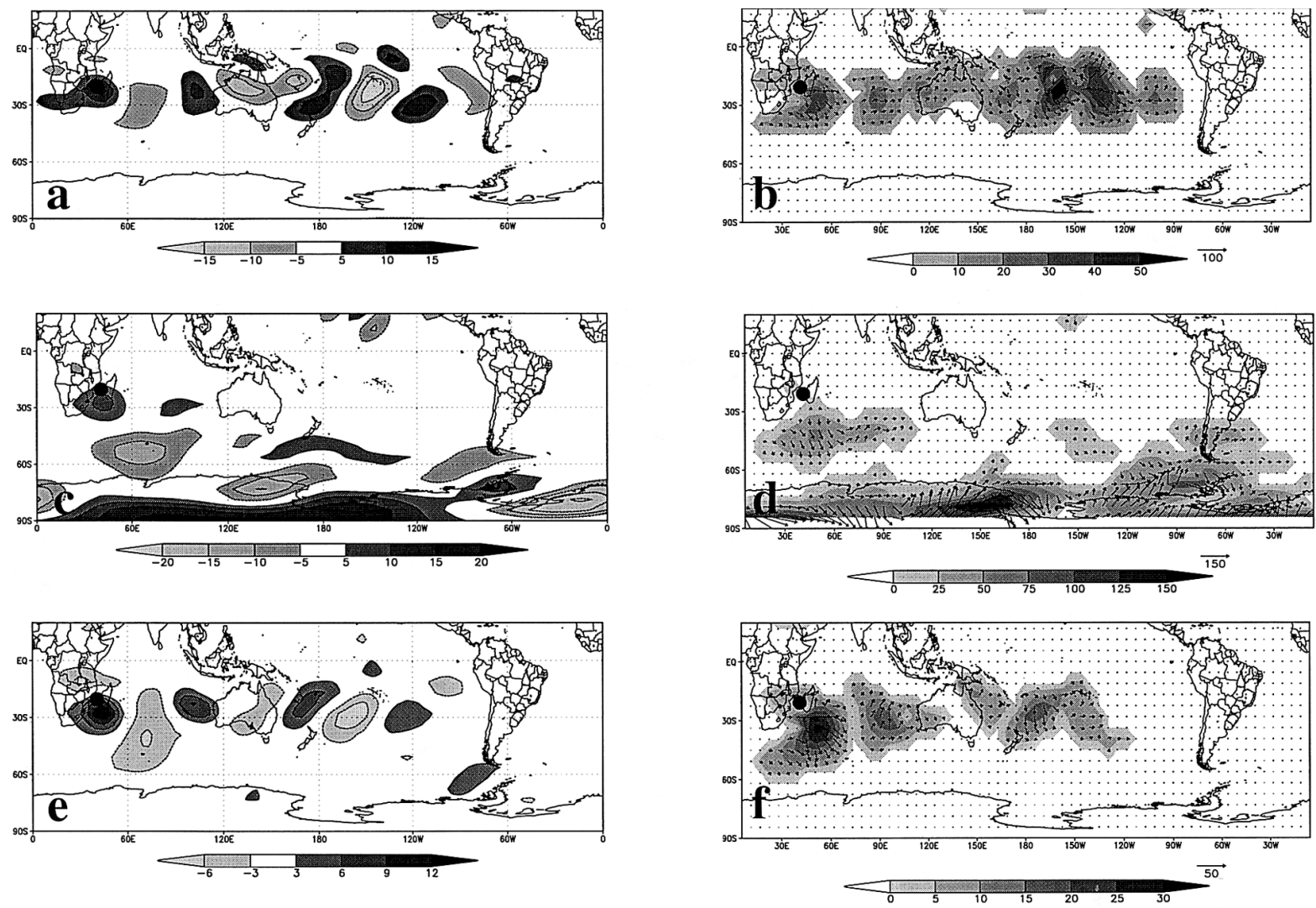

Fig. 8. Relative vorticity anomalies $\left(\cdot 10^{-6} \mathrm{~s}^{-1}\right)$ for (a) PRE-BL1, (c) BL1 and (e) POST-BL1, and direction (arrows) and magnitude (shading and length of the arrow) of the vector wave activity flux $\mathbf{M}_{T}\left(\mathrm{~m}^{2} \mathrm{~s}^{-2}\right)$ for (b) PRE-BL1, (d) BL1 and (f) POST-BL1. The solution refers to day 20 of model integration, with a subtropical circular forcing positioned at $20^{\circ} \mathrm{S}, 40^{\circ} \mathrm{E}$ (black circle in the figures). Only fields of $\mathbf{M}_{T}$ equal to or greater than $10 \%$ of the magnitude of the reference vector indicated below the figure are shown.

higher latitudes would be possible due to the increase in $K_{S}$ values in that direction. A discontinuity, through which the waves with wavenumber as large as 4 could possibly penetrate to higher latitudes and become trapped south of $60^{\circ} \mathrm{S}$, is observed over the high latitudes of the Indian Ocean sector of figure $5 \mathrm{~b}$. The numerical result showing an intense wave propagation at higher latitudes seems to confirm the Rossby waves trapped south of $60^{\circ} \mathrm{S}$.

Figure 8e allows the examination of the wave propagation during the POST-BL1 period. Again, the subtropical wave train with wavenumber 5 is the most important feature, being similar to the results obtained in AHH95, and the pattern obtained during the PRE-BL1 period (Fig. 8a). However, the wave activity flux (Fig. 8f) is weaker in comparison with Fig.
$8 \mathrm{~b}$, as noticed by the magnitude of the vector $\mathbf{M}_{T}$.

For these first three cases, one can identify changes in the behavior of the Rossby wave propagation pattern during the blocking life cycle, suggesting an association with the changes in the dynamical structure of the basic flow.

\section{b. PRE-BL2, BL2 and POST-BL2 cases: subtropical forcing}

For the period PRE-BL2, the Rossby wave propagation obtained from the barotropic model is shown in Fig. 9a. Again, a zonally-oriented wave propagation along the subtropical jet is characterized for this pre-blocking case. Comparing Figs. 8a and 9a (referring to two preblocking situations), we note a slight southward displacement of the zonal axis of the 

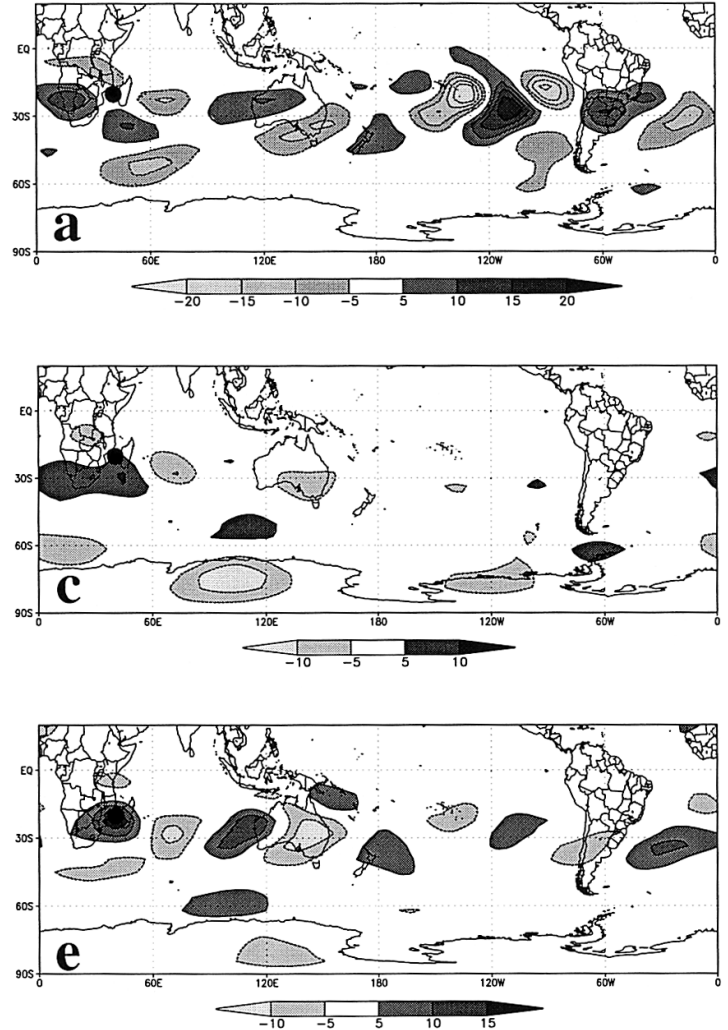
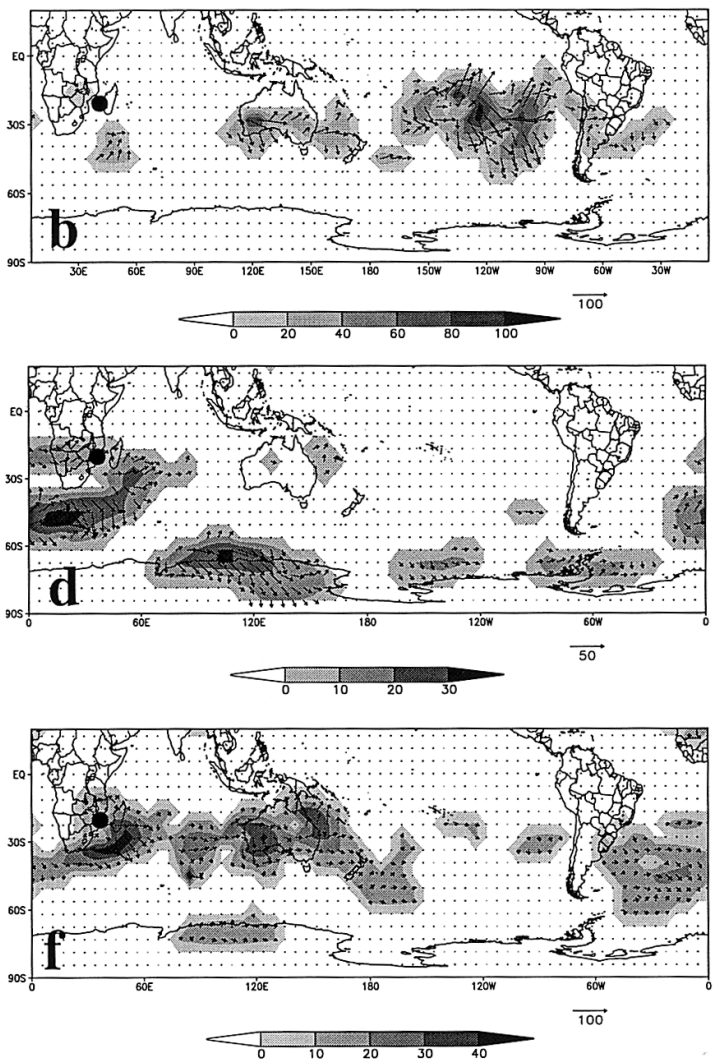

Fig. 9. Same as Fig. 8, but for: (a) and (b) PRE-BL2, (c) and (d) BL2, (e) and (f) POST-BL2.

Rossby wave train for the second case. This can be understood if we consider that the subtropical maximum in $K_{S}$ for the PRE-BL2 period is located farther south $\left(\sim 32^{\circ} \mathrm{S}\right)$ in comparison with the PRE-BL1 period $\left(\sim 25^{\circ} \mathrm{S}\right)$ as can be seen from Figs. 5a and 6a.

An important characteristic observed from the analysis of the wave activity flux (Fig. 9b) is the development of a maximum activity on the longitudinal sector near the zone where a blocking anticyclone was about to form. This result is similar to that observed for the PREBL1 case (Fig. 8b). Hence, from the two preblocking situations, the numerical solutions suggest a possible signal in the Rossby wave propagation that seems to be associated with the subsequent development of a blocking system, which is in agreement with previous studies (Nakamura 1994; Naoe et al. 1997).

Figure 9c shows the wave propagation structure for period BL2. We notice that the Rossby wave activity is more intense at higher lat- itudes, but with smaller amplitudes when compared with the BL1 case. Since the blocking system, in this case, is positioned in a longitudinal belt that is farther away from the forcing region, the comparatively weaker Rossby wave activity at high latitudes is possibly due to a less effective influence of the blocking pattern on the wave propagation. As for BL1, the subtropical propagation has weakened significantly such that the contour intervals used in the plot cannot capture it.

For situation POST-BL2, Fig. 9e shows that the wave propagation has its main axis back to the subtropical region, though with smaller amplitude when compared with Fig. 9a. The waveactivity flux in the subtropics has weakened substantially over the formerly blocked region in the Pacific and it is now most apparent over the Indian Ocean (Fig. 9f).

The results discussed so far show that the life cycle of both blocking cases seems to influence the Rossby wave propagation in a similar fash- 

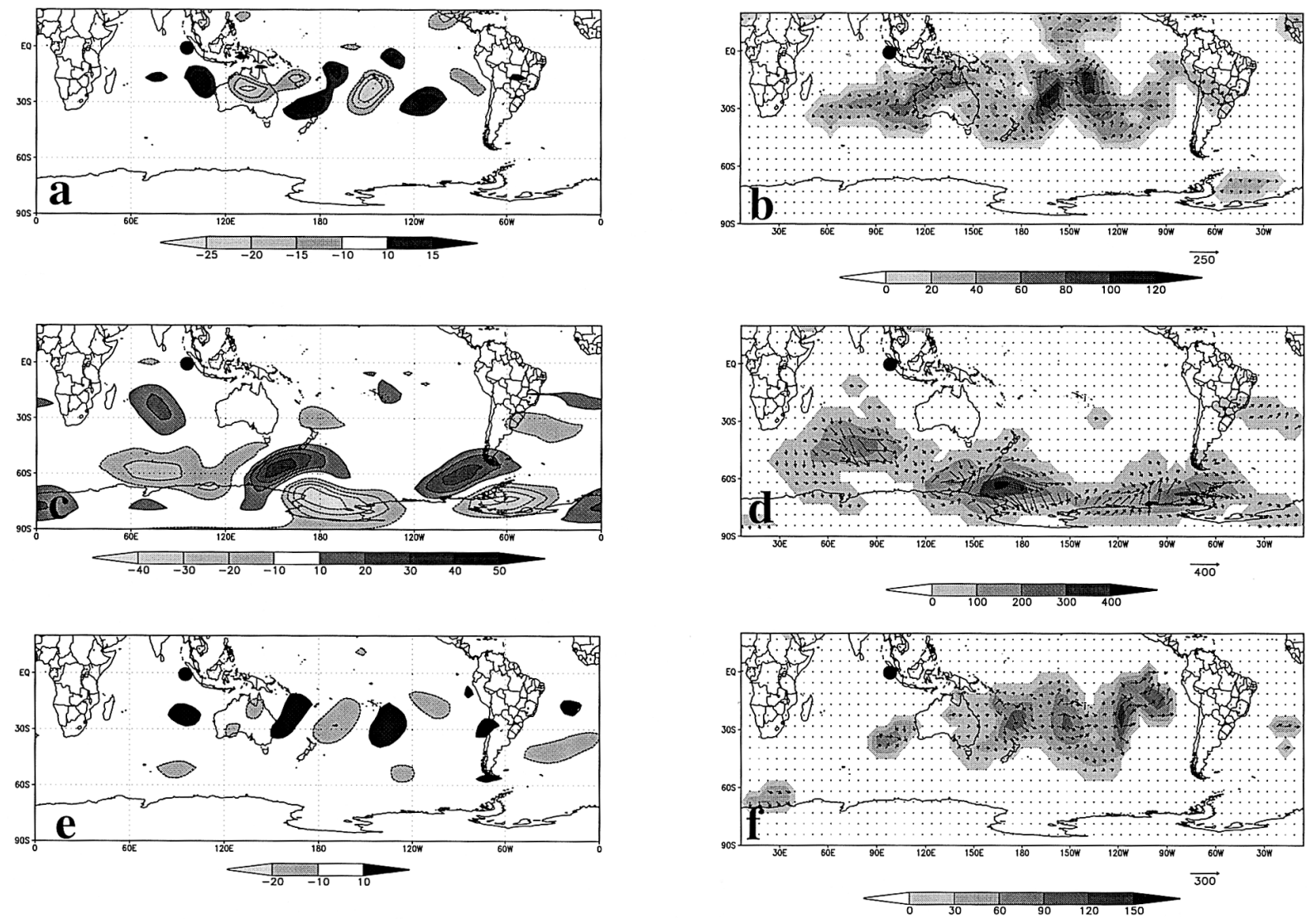

Fig. 10. Same as Fig. 8 ((a) and (b) PRE-BL1, (c) and (d) BL1, (e) and (f) POST-BL1), but with a tropical ellipsoidal forcing positioned at $0^{\circ}, 95^{\circ} \mathrm{E}$ (black circle in the figures).

ion, regardless of their longitudinal position. In the next section, we evaluate if the same pattern holds if the forcing is located in different latitudes.

\section{c. PRE-BL1, BL1 and POST-BL1 cases: tropical forcing}

For the numerical experiments to be discussed in this section, the shape and position of the tropical forcing were defined by the analysis of the OLR anomalies with regard to the respective monthly climatological means, as explained in Section 3.

Figure 10a indicates the Rossby wave activity triggered by an elliptical tropical forcing placed at $0^{\circ}, 90^{\circ} \mathrm{E}$ for the PRE-BL1 period. Note that the subtropical propagation is the most evident signal, and coincides with the maximum $K_{S}$ for this region. The amplitude of the vorticity anomalies, and wave activity flux (Fig.
$10 \mathrm{~b}$ ), are larger than the ones obtained with the experiment with subtropical forcing (Figs. 8a and $8 b$ ), but they are in phase. This result indicates the robustness of this mode in terms of the forcing position. Once again, one can distinguish (Fig. 10b) a maximum magnitude of the $\mathbf{M}_{T}$ vector field in the longitudinal zone where the blocking develops in the following period.

During period BL1, the wave activity triggered by the tropical forcing is more intense at higher latitudes of the Pacific Ocean (Figs. 10c and $10 \mathrm{~d}$ ), and it shows larger amplitudes in comparison with Fig. 8c. It is interesting to notice that a maximum of wave activity flux occurs to the south of New Zealand and it coincides with discontinuities on the $K_{S}$ field (Fig. 5b) associated with a weak meridional gradient of the basic state absolute vorticity (i.e., $\quad \beta^{*}=\partial f / \partial y+\partial^{2} \bar{u} / \partial y^{2} \approx 0$ ). In addition, 
there is a secondary maximum of $\mathbf{M}_{T}$ to the south of South America, where, again, values of $K_{S}$ associated with $\beta^{*}$ equal to zero are observed (Fig. 5b).

At this point it should be stressed that it is possible to interpret some of these patterns as modes growing partially due to barotropic instability in the basic state, because of the change in the sign of $\beta^{*}$ in that region. The strong Newtonian damping suppresses most of the growth by pure barotropic instability, but may still allow some decaying normal modes to interact with forced modes associated with the Rossby wave source. It is important to say that the linear theory for Rossby wave propagation holds better for a zonally symmetric flow. Its application to a zonally asymmetric atmosphere is possible, but certainly has some limitations and may not account for $100 \%$ of the amplitude of the vorticity anomalies.

The numerical results for the POST-BL1 episode indicates maximum wave activity back in the subtropical region (Figs. 10e and 10f). Although the local response to the forcing is comparatively weaker, the general pattern of the vorticity anomalies and the $\mathbf{M}_{T}$ vector are comparable to PRE-BL1 shown in Figs. 10a and $10 \mathrm{~b}$.

The numerical results with an elliptical tropical forcing for the periods PRE-BL1, BL1 and POST-BL1 showed, from a qualitative standpoint, a good agreement with the structure discussed for the subtropical forcing. During the blocking episodes, the wave activity in the subtropical sector becomes less important, in contrast with the periods without blocking.

\section{d. PRE-BL2, BL2 and POST-BL2 cases: tropical forcing}

For the three numerical experiments discussed in this section, a circular tropical forcing was placed at $75^{\circ} \mathrm{E}, 10^{\circ} \mathrm{N}$, based on the negative anomalies in OLR shown in Fig. 4d.

Figure 11a shows intense activity of Rossby waves in the subtropical region from west of Australia to the South Atlantic region for the PRE-BL2 case. There is a good concordance between this pattern and the corresponding one obtained with the subtropical forcing. The vorticity anomalies in both cases show a slight NW/SE orientation in the wave train over Australia, Central Pacific and South America. Fig- ure 6a shows similar orientation in the bands of maximum $K_{S}$ for the same regions. In particular, these local maxima in $K_{S}$ are associated with the subtropical jet streaks observed in Southern Australia, Central Pacific and South America (Fig. 3a), which agrees with the reasoning that jet streams are efficient waveguides for Rossby waves.

Once more, the wave activity flux (Fig. 11b) shows a maximum value where the blocking would develop in the subsequent period.

The numerical results for case BL2 (Fig. 11c) display a clear intensification of the wave activity at high latitudes. For this case, a wave train propagating along a subtropical waveguide is still distinguishable (Fig. 11d), though associated with relatively weak wave activity.

Finally, the solution obtained for the POSTBL2 case with tropical forcing (Fig. 11e) shows a propagation pattern that is similar to the one found with the subtropical forcing (compare with Fig. 9e), with the subtropical wave train displaying a wavenumber 5 . However, the vorticity anomalies from the tropical forcing experiment present larger amplitudes. The wave activity flux shown in Fig. $11 \mathrm{f}$ is similar to the results discussed for both POST-BL1 and POSTBL2 cases.

In spite of all limitations associated with the use of more realistic basic flows, the linear theory for the Rossby wave propagation seems to provide the necessary information to understand most of the results shown here.

\section{e. Non-linear experiments}

In order to evaluate if non-linear processes could affect the numerical results discussed above, we repeated all the numerical experiments using a non-linear version of the barotropic model (figures not shown), where all other parameters were kept the same. It was noticed that the amplitudes of the vorticity anomalies and the wave activity flux were smaller in comparison with the linear experiments. However, from a qualitative standpoint, the propagation patterns did not show any significant change, keeping the same features discussed for the linear case. In summary, the non-linear terms contributed to a reduction in the amplitude of the waves, but did not affect their phase or the propagation pattern. This is consistent with other results discussed in the 

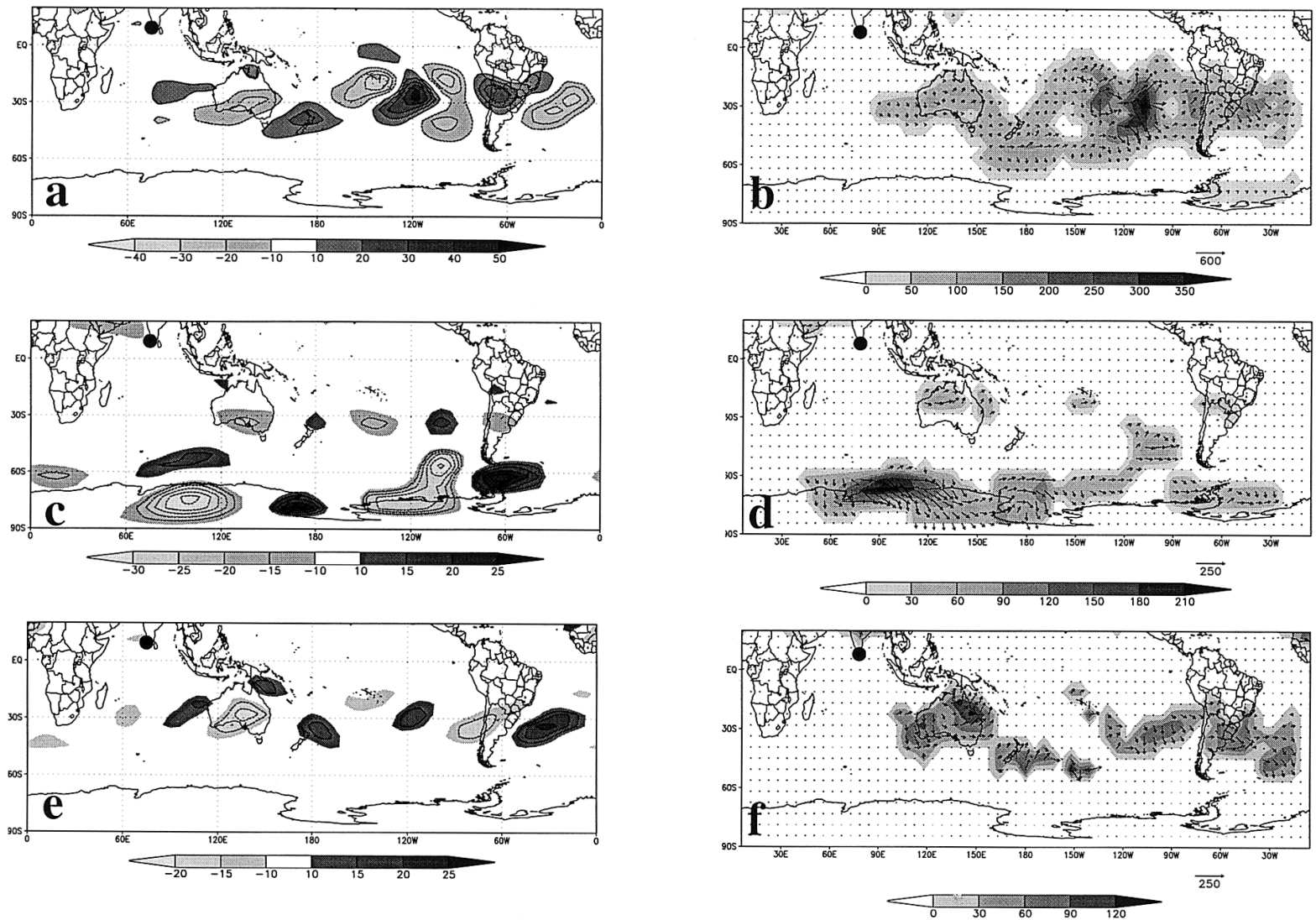

Fig. 11. Same as Fig. 10, but with a tropical circular forcing positioned at $10^{\circ} \mathrm{N}, 75^{\circ} \mathrm{E}$ (black circle in the figures), for: (a) and (b) PRE-BL2, (c) and (d) BL2, (e) and (f) POST-BL2.

literature, such as in Ting and Held (1990) and Grimm and Silva Dias (1995).

\section{Summary and concluding remarks}

The examination of the influence of atmospheric blocking on the propagation of barotropic Rossby waves was the main objective of this study. Two blocking cases embedded in $\mathrm{SH}$ winter flows were selected, and a barotropic model was used to analyze the Rossby wave activity during the life cycle of these systems. The main goal was to identify patterns that could characterize the wave propagation not only during the presence of blocking, but also prior to its establishment, and after its decay. The forcing, represented by an anomalous divergence, was positioned at tropical and subtropical latitudes. For the tropical experiments, the shape and positioning of the forcing were defined after the examination of the OLR anomaly fields.

The numerical results were analyzed in thelight of the linear theory for the barotropic Rossby wave propagation (Hoskins et al. 1977; Branstator 1983; Karoly 1983a; Hoskins and Ambrizzi 1993; AHH95). Stationary wavenumber $\left(K_{S}\right)$ fields were determined for the six selected basic flows. As expected from linear theory, the $K_{S}$ distribution stressed the importance of jet streams as efficient waveguides, with a good agreement between the position of these features and the zonally oriented bands of local maxima of $K_{S}$.

These aspects gave confidence in applying the linear theory for the interpretation of the numerical results, in spite of its limitations when considering a zonally asymmetric atmosphere. The numerical results were consistent 
with the main features depicted by the $K_{S}$ distribution.

High values of $K_{S}$ were found at higher latitudes along the longitudinal belt where the two blocking episodes were observed. The high values of $K_{S}$ on the sub-polar sector suggested the possibility of an enhanced Rossby wave propagation in this region. Based on linear theory and employing a barotropic model it was possible to assess this aspect, at least in a qualitative manner.

The main features highlighted by the numerical results for the Rossby wave activity during the life cycle of the blocks can be summarized as following:

(a) Preceding the blocking onset:

During the periods immediately prior to the blocking onset the wave propagation along a subtropical waveguide was the most relevant feature. This propagation was in good agreement with the orientation and latitudinal position of the $K_{S}$ maxima in the subtropical sector, and it is consistent with the results discussed in AHH95.

In addition, for the pre-blocking situations, maximum values in wave activity flux were found on the longitudinal sector where the blocking patterns would develop in the next period. This feature indicates a possible (and important) sensitivity of barotropic Rossby wave activity to the onset of the blocking events analyzed. Previous studies for the Northern Hemisphere have also discussed similar patterns (Nakamura 1994; Naoe et al. 1997; Nakamura et al. 1997). Moreover, Nutter et al. (1998) suggested that the planetary wave structure of the atmosphere could corroborate to skillful ensemble predictions of transitions to a blocked pattern at longer lead times (e.g., eight days).

If our result is in fact representative of typical blocking episodes in the $\mathrm{SH}$, then it suggests that a constant monitoring of planetary Rossby waves via wave activity flux could be useful in improving the skill in forecasting the onset of SH blocking during the winter. In this context, it is interesting to quote a statement by Buizza and Molteni (1996): "If the onset of blocks is indeed strongly conditioned by the preexisting planetary wave structure, then atmospheric global circulation models that underestimate the forcing of planetary waves should provide a very poor simulation of blocking".

(b) Blocking stage and subsequent period:

For situations BL1 and BL2, the numerical results showed a stronger Rossby wave activity at sub-polar latitudes and a suppression (but not complete elimination) of the subtropical propagation. As before, the linear theory for Rossby wave propagation provided necessary insight to understand this result. The presence of relatively high values of $K_{S}$ in the high latitudes of the $\mathrm{SH}$ for both BL1 and BL2 periods seemed to favor the wave propagation in this sector.

For the periods immediately after blocking decay, the subtropical wave propagation again became the most important feature, representing a pattern similar to that obtained by AHH95.

It should be emphasized that, in the situations studied here, a transition of the main axis of wave propagation from subtropical to subpolar and back to subtropical, was obtained following the sequence PRE-BL1 (PRE-BL2)BL1 (BL2)-POST-BL1 (POST-BL2). The positioning of the forcing in different latitudes did not alter this pattern qualitatively.

At this point, it is relevant to mention the investigation by Yang and Hoskins (1996). They argued that the propagation of non-zero frequency Rossby waves, which display a distinct behavior from the stationary waves (i.e., the ones studied here), can be more important in accounting for low-frequency wave features in the atmosphere when one is considering the impact of local meteorological events, such as a slow moving block. Nevertheless, our results, while not diminishing the importance of the non-zero frequency waves, indicate that the main characteristics of the Rossby wave dispersion during episodes of blocking can still be well understood by applying the wave theory based on stationary waves.

Another important point is that the analysis carried out in the present study focused mainly on the forced modes of the barotropic Rossby waves, although some evidence of growth by barotropic instability was also found (such as some strong activity in regions associated with $\beta^{*}=0$, i.e., where it changes sign). The presence of these modes, however, does not jeopardize the interpretation of the numerical results, because the use of a high Newtonian damping 
suppresses the modes that grow by pure barotropic instability, and precludes the free perturbations (normal modes) to become the most dominant modes.

Observational studies, preferably encompassing several blocking cases, are encouraged in order to confirm the model results obtained here. The selection of two cases representing typical blocking situations for the $\mathrm{SH}$ winter was done in order to keep the results as representative as possible for the winter conditions. In spite of that, further studies based on a climatological approach are desirable in order to verify if the wave propagation features obtained here are, in fact, representative for most blocking episodes.

Finally, it should be stressed that the main goal of the present investigation was to examine the influence of blocking on the Rossby wave propagation, and not the onset of blocking itself. No analysis on the barotropic energy conversion during the blocking onset (Buizza and Molteni 1996) was carried out. The authors recognize that the result obtained for the preblocking situations justifies the need for future investigations examining this aspect for $\mathrm{SH}$ blocking events.

\section{Acknowledgments}

This work is part of the first author's M.Sc. thesis at the Instituto Astronômico e Geofísico (IAG) of the Universidade de São Paulo (USP). The authors thank Dr. H.L. Tanaka and two anonymous reviewers for the relevant remarks that contributed to the improvement of the original manuscript. This work was sponsored by $\mathrm{CNPq}$ (Conselho Nacional de Desenvolvimento Científico e Tecnológico) and CAPES (Fundação Coordenação de Aperfeiçoamento de Pessoal de Nível Superior) during distinct periods of the research. Finally the authors acknowledge CESUP-UFRGS (Centro Nacional de Supercomputação/Universidade Federal do Rio Grande do Sul) for the computational support.

\section{References}

Ambrizzi, T., B.J. Hoskins, and H.-H. Hsu, 1995: Rossby wave propagation and teleconnection patterns in the austral winter. J. Atmos. Sci., 52, 3661-3672.
Austin, J.F., 1980: The blocking of middle latitude westerly winds by planetary waves. Quart. J. Roy. Meteor. Soc., 106, 327-350.

Berbery, E.H., J. Nogués-Paegle, and J.D. Horel, 1992: Wavelike Southern Hemisphere extratropical teleconnections. J. Atmos. Sci., 49, $155-177$.

Borges, M.D. and P.D. Sardeshmukh, 1995: Barotropic Rossby wave dynamics of zonally varying upper-level flows during northern winter. J. Atmos. Sci., 52, 3779-3796.

Branstator, G., 1983: Horizontal energy propagation in a barotropic atmosphere with meridional and zonal structure. J. Atmos. Sci., 40, 16891708.

Buizza, R. and F. Molteni, 1996: The role of finitetime barotropic instability during transition to blocking. J. Atmos. Sci., 53, 1675-1697.

Colucci, S.J. and T.L. Alberta, 1996: Planetary-scale climatology of explosive cyclogenesis and blocking. Mon. Wea. Rev., 124, 2509-2520.

— and D.P. Baumhefner, 1998: Numerical prediction of the onset of blocking: a case study with forecast ensembles. Mon. Wea. Rev., 126, 773-784.

Coughlan, M.J., 1983: A comparative climatology of blocking action in the two hemispheres. Aust.Meteor. Mag., 31, 3-13.

Egger, J., W. Metz, and G. Müller, 1986: Forcing of planetary-scale blocking anticyclones by synoptic-scale eddies. Anomalous Atmospheric Flows and Blocking, Advances in Geophysics, Vol. 29, R. Benzi, B. Saltzman, and A.C. WiinNielsen, Eds., Academic Press, 183-198.

Grimm, A. and P.L. Silva Dias, 1995: Use of barotropic models in the study of the extratropical response to tropical heat sources. J. Meteor. Soc. Japan, 73, 765-780.

Hansen, A.P. and T.C. Chen, 1982: A spectral energetics study of atmospheric blocking. Mon. Wea. Rev., 110, 1146-1165.

Holopainen, E.O. and C. Fortelius, 1987: Highfrequency transient eddies and blocking. $J$. Atmos. Sci., 44, 1632-1645

Hoskins, B.J., 1980: Representation of the Earth topography using spherical harmonics. Mon. Wea. Rev., 108, 111-115.

, A.J. Simmons, and D.G. Andrews, 1977: Energy dispersion in a barotropic atmosphere. Quart. J. Roy. Meteor. Soc., 103, 553-567.

- and D.J. Karoly, 1981: The steady linear response of a spherical atmosphere to thermal and orographic forcing. J. Atmos. Sci., 38, $1179-1196$.

and T. Ambrizzi, 1993: Rossby wave propagation on a realistic longitudinally varying flow. J. Atmos. Sci., 50, 1661-1671. 
Illari, L. and J.C. Marshall, 1983: On the interpretation of eddy fluxes during a blocking episode. $J$. Atmos. Sci., 40, 2232-2242.

Julian, P., 1984: Objective analysis in the tropics: a proposed scheme. Mon. Wea. Rev., 112, 17521767.

Karoly, D.J., 1983a: Rossby wave propagation in a barotropic atmosphere. Dyn. Atmos. Oceans, 7, 111-125.

, 1983b: Atmospheric teleconnections, forced planetary waves and blocking. Aust. Meteor. Mag., 31, 51-56.

Krishnamurty, T.N. and S. Low-Nam, 1986: On the relationship between the outgoing long wave radiation and the divergent circulation. $J$. Meteor. Soc. Japan, 64, 709-718.

Lejenäs, H. and H. Økland, 1983: Characteristics of Northern Hemisphere blocking as determined from a long time series of observational data. Tellus, 35A, 350-362.

and R.A. Madden, 1992: Traveling planetaryscale waves and blocking. Mon. Wea. Rev., 120, 2821-2830.

Li, Z., A. Barcilon, and I.M. Navon, 1999: Study of block onset using sensitivity perturbations in climatological flows. Mon. Wea. Rev., 127, 879900.

Lindzen, R.S., 1986: Stationary planetary waves, blocking and interannual variability. Anomalous Atmospheric Flows and Blocking, Advances in Geophysics, Vol. 29, R. Benzi, B. Saltzman, and A.C. Wiin-Nielsen, Eds., Academic Press, 251-273.

Lupo, A.R. and P.J. Smith, 1995: Planetary and synoptic-scale interactions during the life cycle of a mid-latitude blocking anticyclone over the North Atlantic. Tellus, 47A, 575-596.

and L.F. Bosart, 1999: An analysis of a relatively rare case of continental blocking. Quart. J. Roy. Meteor. Soc., 125, 107-138.

Marques, R.F.C. and V.B. Rao, 1999: A diagnosis of a long-lasting blocking event over the southeast Pacific Ocean. Mon. Wea. Rev., 127, 17611776.

Metz, W., 1986: Transient cyclone-scale vorticity forcing of blocking highs. J. Atmos. Sci., 43, 1467-1483.

Mullen, S.L., 1987: Transient eddy forcing of blocking flows. J. Atmos. Sci., 44, 3-22.

Nakamura, H., 1994: Rotational evolution of potential vorticity associated with a strong blocking flow configuration over Europe. Geophys. Res. Lett., 21, 2003-2006.

- and J.M. Wallace, 1993: Synoptic behaviour of baroclinic eddies during blocking onset. Mon. Wea. Rev., 121, 1892-1903.
, M. Nakamura, and J.L. Anderson, 1997: The role of high- and low-frequency dynamics in blocking formation. Mon. Wea. Rev., 125, 20742093.

Naoe, H., Y. Matsuda, and H. Nakamura, 1997: Rossby wave propagation in idealized and realistic zonally varying flows. J. Meteor. Soc. Japan, 75, 687-700.

Nutter, P.A., S.L. Mullen, and D.P. Baumhefner, 1998: The impact of initial condition uncertainty on numerical simulations of blocking. Mon. Wea. Rev., 126, 2482-2502.

Plumb, R.A., 1986: Three dimensional propagation of transient quasi-geostrophic eddies and its relationship with the eddy forcing of the timemean flow. J. Atmos. Sci., 43, 1657-1678.

Pondeca, M.S., A. Barcilon, and X. Zou, 1998: The role of wave breaking, linear instability and PV transport in model block onset. J. Atmos. Sci., 55, 2852-2873.

Renwick, J.A., 1998: ENSO-related variability in the frequency of South Pacific blocking. Mon. Wea. Rev., 126, 3117-3123. and M.J. Revell, 1999: Blocking over the South Pacific and Rossby wave propagation. Mon. Wea. Rev., 127, 2233-2247.

Rex, D.F., 1950: Blocking action in the middle troposphere and its effect upon regional climate. Part I: an aerological study of blocking action. Tellus, 2, 196-211.

Sardeshmukh, P.D. and B.J. Hoskins, 1984: Spatial smoothing on the sphere. Mon. Wea. Rev., 112, 2524-2529.

- and -1988 : The generation of global rotational flow by steady idealized tropical divergence. J. Atmos. Sci., 45, 1228-1251.

Shutts, G.J., 1983: The propagation of eddies in diffluent jetstreams: eddy vorticity forcing of 'blocking' fields. Quart. J. Roy. Meteor. Soc., 109, 737-761.

, 1986: A case study of eddy forcing during an Atlantic blocking episode. Anomalous Atmospheric Flows and Blocking, Advances in Geophysics, Vol. 29, R. Benzi, B. Saltzman, and A.C. Wiin-Nielsen, Eds., Academic Press, 135162.

Sinclair, M.R., 1996: A climatology of anticyclones and blocking for the Southern Hemisphere. Mon. Wea. Rev., 124, 245-263.

Takaya, K. and H. Nakamura, 1997: A formulation of a wave-activity flux for stationary Rossby waves on a zonally varying basic flow. Geophys. Res. Lett., 24, 2985-2988.

and -2001 : A formulation of a phaseindependent wave-activity flux for stationary and migratory quasigeostrophic eddies on a 
zonally varying basic flow. J. Atmos. Sci., 58, 608-627.

Tibaldi, S. and F. Molteni, 1990: On the operational predictability of blocking. Tellus, 42A, 343364.

E. Tosi, A. Navarra, and L. Pedulli, 1994: Northern and Southern Hemisphere seasonal variability of blocking frequency and predictability. Mon. Wea. Rev., 122, 1971-2003.

, P. Ruti, E. Tosi, and M. Maruca, 1995: Operational predictability of winter blocking at ECMWF: an update. Ann. Geophys., 13, 305317.

Ting, M. and I. Held, 1990: The stationary wave response to a tropical SST anomaly in an idealized GCM. J. Atmos. Sci., 47, 25462566.

Trenberth, K.E. and K.C. Mo, 1985: Blocking in the Southern Hemisphere. Mon. Wea. Rev., 113, 321.

Tsou, C.-H. and P.J. Smith, 1990: The role of synoptic/planetary-scale interactions during the development of a blocking anticyclone. Tellus, 42, 174-193.

Willet, H.C., 1949: Long-period fluctuations of the general circulation of the atmosphere. $J$. Meteor., 6, 34-50.

Yang, G.Y. and B.J. Hoskins, 1996: Propagation of Rossby waves of nonzero frequency. J. Atmos. Sci., 53, 2365-2378. 